\title{
Simple inertial methods for solving split variational inclusions in Banach Spaces
}

\author{
YAN TANG ${ }^{1}$, Aviv Gibali ${ }^{2}$, and Yeol Je Cho ${ }^{3}$ \\ ${ }^{1}$ Chongqing Technology and Business University \\ ${ }^{2}$ ORT Braude College \\ ${ }^{3}$ Gyeongsang National University
}

June 19, 2020

\begin{abstract}
In this paper, we introduce two simple inertial algorithms for solving the split variational inclusion problem in Banach spaces. Under mild and standard assumptions we establish the weak and strong convergence of the proposed methods, respectively. As theoretical realization we study existence of solutions of the split common fixed point problem in Banach spaces.

Several numerical examples in finite and infinite dimensional spaces compare and illustrate the performances of our schemes. Our work generalize and extend some recent relate results in the literature and also propose a simple and applicable method for solving split variational inclusions.

2000 Mathematics Subject Classification: 65K10; 65K05; 47H10; 47L25.

Keywords: Split variational inclusion problem; inertial technique; Banach spaces.

\section{Hosted file}

Inertial SVI140620.pdf available at https://authorea.com/users/335207/articles/461061-simpleinertial-methods-for-solving-split-variational-inclusions-in-banach-spaces
\end{abstract}

